\title{
ANÁLISIS DE LA PRODUCCIÓN DE VIVEROS Y DE LA COMERCIALIZACIÓN DE PLÁNTULAS EN EL ÁREA DE INFLUENCIA DEL CANTÓN QUEVEDO, PROVINCIA DE LOS RÍOS PARA EL ESTABLECIMIENTO DE PLANTACIONES DE TECA (Tectona grandis L.F.)
}

\author{
Gorki Teófilo Díaz Coronel ${ }^{1,2}$; ${ }^{\circ}$ Emma Danielly Torres Navarrete ${ }^{1,2}$, Shirley Álava Ormaza ${ }^{3}$, \\ Betty González Osorio ${ }^{1,4}$; Nicolás Cruz Rosero ${ }^{1,5}$ \\ ${ }^{1}$ Unidad de Investigación Científica y Tecnológica, Universidad Técnica Estatal de Quevedo, $\mathrm{km} 7$ vía \\ Quevedo - El Empalme, C.P.73. Mocache, Los Ríos, Ecuador. \\ ${ }^{2}$ Facultad de Ciencias Pecuarias, Universidad Técnica Estatal de Quevedo, $\mathrm{km} 7$ vía a El Empalme, \\ Mocache, Los Ríos, Ecuador. ${ }^{\bullet}$ edatona@yahoo.es \\ ${ }^{3}$ Universidad Técnica de Manabí, Facultad de Ciencias Administrativas y Económicas \\ ${ }^{4}$ Facultad de Ciencias Empresariales, Universidad Técnica Estatal de Quevedo, km 1 1/2 vía \\ Quevedo-Santo Domingo de los Tsáchilas, Quevedo, Los Ríos, Ecuador. \\ ${ }^{5}$ Laboratorio de Biotecnología, Universidad Técnica Estatal de Quevedo, $\mathrm{km} 11 / 2$ vía \\ Quevedo-Santo Domingo de los Tsáchilas. Quevedo, Los Ríos, Ecuador
}

RESUMEN

M uchos inversionistas y productores de madera de teca del Ecuador se abastecen de plántulas producidas por pequeños viveristas no tecnificados, siendo ellos los que tienen la mayor oferta de plántulas; la falta de tecnificación puede ser un factor limitante en el desarrollo normal de las plantaciones comerciales lo cual no garantiza la obtención de plantaciones vigorosas, sanas y de alta producción de madera. Desde ese punto de vista es necesario conocer todo el proceso de producción de las plántulas, así como el origen y manejo de las semillas, costos de producción y sistemas de comercialización. El estudio se realizó en el área de influencia de la provincia de Los Ríos, Ecuador, debido a que es en esta provincia donde están establecidos la mayor parte de los viveros de teca que abastecen la demanda existente en el Litoral y Amazonía ecuatoriana. Se determinó que en los viveros pequeños los dueños viven en su propiedad, realizan actividades de campo, supervisión o de comercialización; no así en los viveros grandes donde es el técnico quien supervisa las labores. El viverista grande utiliza semilla certificada y, los pequeños viveristas usan semillas cosechadas en árboles de la localidad. Los costos de las plántulas a nivel de pequeños viveristas y de productor de pseudoestacas fue de 0.07 USD, y a nivel de productor tecnificado y de plántulas in vitro 0.19 USD. La mejor rentabilidad se obtiene a nivel de pseudoestacas $(36 \%)$ seguido de la producción de plántulas in vitro $(31 \%)$. La demanda requiere para los próximos años una cantidad aproximada de tres a cuatro millones de plántulas, mientras que la oferta no supera los dos millones y medio, existiendo una demanda insatisfecha que deberá ser cubierta por los pequeños productores, lo cual se convierte en un reto pues deberán establecer alianzas estratégicas para lograr costos de producción competitivos.

Palabras claves: balsa, Teca, viveros, plántulas, seudoestacas, costos de producción.

Recibido: noviembre, 2009. Aceptado: Abril, 2010.

Publicado como ARTÍCULO en Ciencia y Tecnología 3(2): 13-20. 2010
$\mathrm{M}$ any investors and producers of teak wood in Ecuador without supplies from seedlings produced by small plant nurseries no modern technology, and they have the largest supply of seedlings, the technification can be a limiting factor in normal development of commercial plantations which does not guarantee obtaining vigorous plantations, healthy and high-timber production. From this point of view is necessary to know the entire process of production of seedlings as well as the origin and seed management, production costs and marketing systems. The study was realized in the influence area of the Los Rios province, Ecuador, because in this province there are established most of teak plant nurseries that supply the demand on the ecuadorian. Coast and Amazon. It was found that small nursery owners occupy their own property, carry out field activities, supervisory or marketing, although not in large nurseries where the technician oversees the work. The large plant nursers use certified seed and nursers small plant use seeds harvested trees from in the locality. The costs of seedlings of small plant nursers and producer of stumps was 0.07 USD, and tech producer level and in vitro plantlets 0.19 USD. The best value is obtained at the level of stumps $(36 \%)$ followed by the production of plantlets in vitro $(31 \%)$. The demand for the coming years requires an amount of approximately three to four million of seedlings, while supply does not exceed two million and a half, there is an unsatisfied demand which must be satisfied by small producers, which becomes a challenge because must build strategic alliances to achieve competitive production costs.

Key words: teak, nurseries, seedlings, stumps, production costs. 


\section{INTRODUCCIÓN}

T a teca (Tectona grandis L.F.) es una de las - 1 principales maderas frondosas que existen en el mundo, apreciada por su color claro, su excelente fibra y su durabilidad. Sólo se da de forma natural en la India, Myanmar, la República Democrática Popular de Laos y Tailandia y se ha aclimatado en Java (Indonesia), donde probablemente se introdujo hace 400 a 600 años. También se ha establecido en toda la zona tropical de Asia, en el África tropical (Cote dIvoire, Nigeria, Sierra Leona, República Unida de Tanzania y Togo) y en América Latina y el Caribe (Brasil, Costa Rica, Colombia, Ecuador, El Salvador, Panamá, Trinidad y Tobago, y Venezuela). La teca se ha introducido también en algunas islas de la región del Pacífico (Papua Nueva, Guinea, Fiji y las Islas Salomón) y en el norte de Australia en forma experimental (Chaves y Fonseca, 1991; CORMADERA, 2001; Fonseca, 2004).

Para el caso del Ecuador, la teca fue introducida hace unos 50 años en la Estación Experimental Tropical Pichilingue de Quevedo, demostrando hasta el momento una buena aclimatación y prometedores resultados en lo que hace referencia al crecimiento (CORMADERA, 2001).

Entre todas las especies tropicales de maderas duras -y tal vez entre todas las especies arbóreas- la teca produce una fascinación especial, algo como el oro entre los metales preciosos. Apreciada durante más de 2000 años en su ámbito natural en Asia como madera de construcción extraordinariamente duradera, la teca es hoy codiciada en todo el mundo. Por su excelente estabilidad dimensional y sus cualidades estéticas se utiliza, por ejemplo, para construcciones navales, mobiliario fino y marcos de puertas y ventanas (SICA, 2005).

Las políticas forestales establecidas y que se enmarcan en el Plan Nacional de Forestación y Reforestación (PNFR) dan cuenta de que en el Ecuador existen más de tres millones de hectáreas de tierras con vocación forestal para plantaciones comerciales e industriales, de las cuales 1,8 millones corresponden a la región Costa. Se puede decir que las áreas priorizadas para plantaciones industriales y comerciales consideradas más adecuadas están en las regiones de la Costa y Sierra. En la Costa, las provincias más representativas son: Esmeraldas, Manabí, Guayas y Los Ríos (Ministerio de Ambiente, 2006), lo cual explica el auge de la explotación de madera, especialmente exóticas en el país, siendo la teca una de ellas.

En el Ecuador existen alrededor de unas 24.000 hectáreas cultivadas de teca con una tendencia al incremento. Para tal efecto, se utilizan principalmente plántulas de viveros particulares cuyo origen de la semilla se desconoce; asimismo, el manejo que se realiza en esta fase de la producción de esta valiosa madera. Este tipo de plántulas no garantiza la obtención de plantas vigorosas y fuertes, necesarias para el establecimiento de plantaciones comerciales con una excelente sanidad, buenas características fenotípicas y alta producción de madera. Ante esta situación, es necesario producir semilla certificada, al alcance de todos los viveristas, por lo que se deberá trabajar en el desarrollo de fuentes semilleras (rodales seleccionados, identificados para tal efecto, huerto semillero, etc).

Sobre esta base, el objetivo de esta investigación fue determinar la producción, rentabilidad y comercialización de plántulas de teca a nivel de viveros del área de influencia del cantón Quevedo, provincia de Los Ríos y comparar los costos de producción, y precios de venta con vitroplantas desarrolladas a nivel de laboratorio.

\section{Materiales y Métodos}

$P$ ara obtener la información referente a los orígenes de la semilla de teca, procesos de producción, datos generales de la propiedad, así como costos de producción, precios, volúmenes de venta y sistemas de comercialización se diseñó un formulario de preguntas. El formulario fue aplicado a todos los productores de teca (14) a nivel de vivero (viveristas no tecnificados y tecnificados cuya producción de plántulas la realizan en fundas de plástico y pseudoestacas).

Los resultados de las encuestas debidamente codificados fueron tabulados y analizados estadísticamente. La información que se generó fue resumida en cuadros y figuras, con lo cual se cubrieron los aspectos tratados en los formularios, y en las variables planteadas para la evaluación del estudio.

Referente a la rentabilidad de la producción a nivel de vivero y de laboratorio (producción de vitroplantas), se analizaron los costos y los ingresos, a través de la relación beneficio/costo. Se calculó la estructura de costos de los diferentes rubros agrupados en directos e indirectos que utilizaron los viveristas, y en la producción de vitroplantas. Además, se calculó el costo y el margen de utilidad por planta de los diferentes viveristas y de la producción de vitroplantas

\section{Resultados y Discusión}

nce de los viveristas fueron pequeños no tecnificados con bajo consumo de insumos (Foto 1). Dos viveristas fueron considerados grandes y tecnificados por su mayor uso de insumos y semilla certificada 
(Foto 2); un viverista que producía pseudoestacas con alto consumo de insumos se lo consideró como semitecnificado por no utilizar semilla certificada (Foto 3). Los viveristas tenían un promedio de 11 años dedicados a esta actividad con un rango que va de cuatro a cuarenta años. Los motivos que tienen los productores

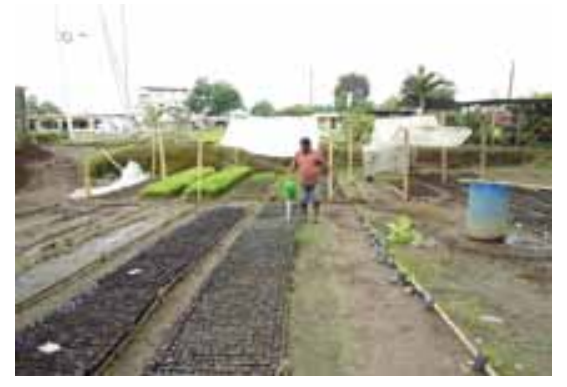

Foto 1. Vivero no tecnificado para dedicarse a la producción de plántulas de teca, a nivel de vivero, son en su orden de importancia: la profesión con un 35.7\%; el aspecto económico 35.7\%; conocen el trabajo $21.5 \%$ y trabajaron en el Ministerio de Agricultura y Ganadería donde recibieron capacitación hace 25 años $7.1 \%$

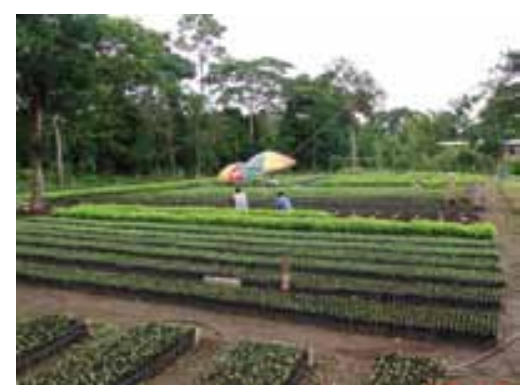

Foto 2. Vivero tecnificado

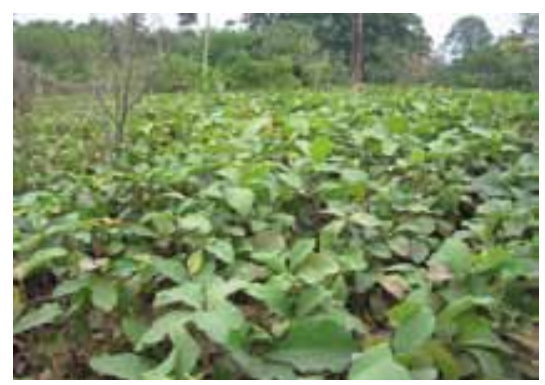

Foto 3. Vivero semi tecnificado

Los viveros están localizados en un $64 \%$ en la localidad de Quevedo; 14.3\% en Mocache y Valencia, respectivamente y un $7.1 \%$ en el cantón Buena Fé. La superficie que los viveristas tienen para la producción de plántulas de teca está entre 0.25 y 2.5 ha.

Paralelamente a la producción de plántulas de teca un $50 \%$ de los productores viveristas recolectan la "semilla" en los meses de septiembre a noviembre de cada año, coincidiendo con CORMADERA (2001), quien indica que la recolección de las semillas se la debe realizar en la época seca. Generalmente esta actividad la realizan en las plantaciones existentes en la Estación Experimental Tropical Pichilingue, zona considerada como la mayor fuente semillera del Ecuador (Foto 4) (CORMADERA, 2001), en la vía Quevedo - El Empalme y en algunos árboles de propiedad de la UTEQ. El criterio para la recolección de la "semilla" en algunos productores es que el árbol sea viejo y frondoso con fuste recto y de gran floración con la finalidad de cosechar la mayor cantidad de semilla; sin embargo, no existe un criterio técnico que certifique la calidad de la semilla por lo que se la puede calificar como "semilla reciclada". Cabe destacar que un $28.6 \%$ de los viveristas adquieren semilla certificada de Costa Rica o a PROFAFOR, lo cual garantiza por lo menos la pureza y una buena germinación y vigor de las plántulas; sin embargo, el porcentaje de viveristas que utilizan semilla certificada es bastante bajo.

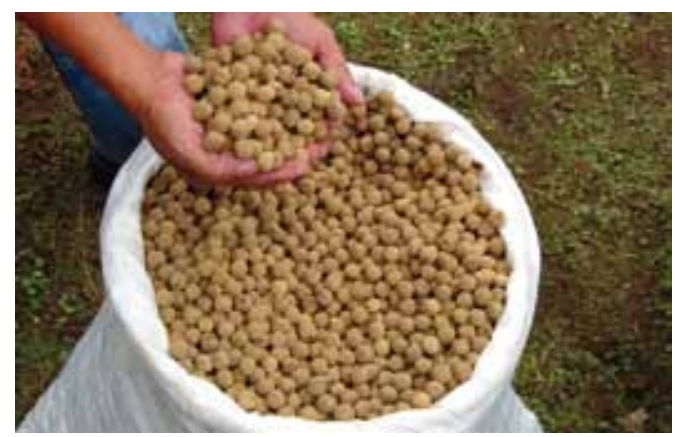

Foto 4. Semilla reciclada de rodales del INIAP

Al realizar el análisis de precios de un kilogramo de semilla, se encontraron diferencias muy notorias. Para aquellos viveristas que reciclan la semilla el costo por kilogramo corresponde a 75 centavos de dólar; mientras que, para aquellos que compran la semilla a campesinos de la zona tiene un costo de 1,5 dólares, y la semilla que se recolecta en el INIAP tiene un precio de 6,0 dólares el kilogramo; por su parte, aquellos que compran semilla certificada lo hacen a 20 y 25 dólares el kilogramo. 
El almacenaje es una actividad importante para conservar la viabilidad y el vigor de la semilla por mayor tiempo, y la forma más adecuada de hacerlo es en cuartos fríos a temperaturas de 3 a $5^{\circ} \mathrm{C}$ y a baja humedad relativa (CORMADERA, 2001). El almacenaje de la semilla es diferente y depende del nivel económico y del conocimiento que tenga cada viverista. Solo los viveristas tecnificados almacenan su semilla en cuartos fríos, mientras que, los pequeños viveristas lo hacen en la casa, especialmente en tanques plásticos, y en algunos casos, no almacenan por que compran lo que van a utilizar inmediatamente.

Referente a la fecha de producción de las plántulas de teca, un 36\% de los viveristas la realiza en el mes de abril, seguido del mes de octubre con un $22 \%$. En el mes de agosto la realiza un 14\% y en los meses de enero, febrero, mayo y septiembre la realiza un $7 \%$ de los viveristas, respectivamente, Figura 1.

La forma de preparar la semilla (tratamientos pregerminativos) con mejores resultados y más utilizada por los viveristas es el remojo de la semilla durante 8 a 15 días, alternando con una asoleada pasando un día (29\%). Este criterio de remojo y asoleada coincide con las recomendaciones que se dan en otros lugares a productores de esta madera (Chaves y Fonseca, 1991; Weaver, 1993; CORMADERA, 2001). Este tratamiento pregerminativo hace que las semillas germinen entre los 12 a 13 días con porcentajes promedios de germinación del $76 \%$, una moda de $80 \%$ y rango que va de 40 a $100 \%$. (Sólo un productor indicó que cuando utiliza semilla vieja o guardada alcanza un porcentaje del $100 \%$ de germinación). Esto coincide con CORMADERA (2001), quien indica que la tasa de germinación en semillas de teca está en el orden del 20 al $80 \%$ y según la literatura casi nunca llega al $100 \%$. Una vez germinadas las semillas éstas son llevadas a las platabandas (germinador) donde permanecen en promedio hasta los 15 días de edad. Siendo el tiempo promedio de germinación 13 días con un rango que varía de 5 a 20 días, siendo la moda 15 días.

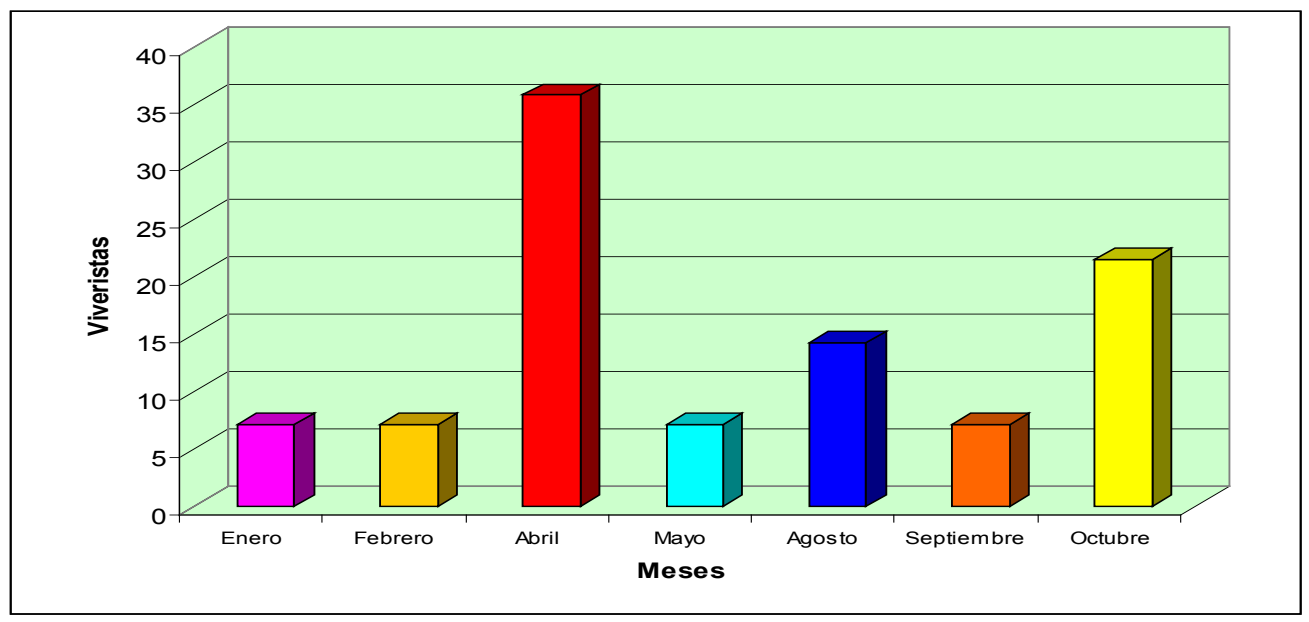

Figura 1. Meses en los cuales los viveristas acostumbran producir las plántulas de teca. Quevedo, 2006

\section{Preparación de las platabandas}

Se encontró una diversidad de formas de manejar las platabandas ajustándose al tamaño del vivero con la finalidad de optimizar los recursos. Las distintas formas de uso son siempre las que mejor se adaptan a las necesidades y ofrecen ventajas a cada viverista; la que más se utiliza es la desinfección de las platabandas (35.7\%), un $14.3 \%$ respectivamente usan tierra arenosa, tierra de la capa arable, tienen las platabandas ya construidas y siembran en surcos, y finalmente, un 7.1\% usan cubetas de germinación, Cuadro 1.

El $100 \%$ de los productores de plántulas de teca realizan actividades de limpieza manual y riego, y un $79 \%$ realiza control fitosanitario.
La fertilización en los viveros la realiza el 93\% de los productores mediante la aplicación de abono foliar u orgánico. El porcentaje restante no lo hace, ya que utiliza tierra de huerta con altos contenidos de materia orgánica. Las actividades de fertilización son unas de las prácticas más importantes en la producción de plantas a nivel de vivero, llegándose a demostrar a través de varios estudios que, al aplicar N, P y K se mejora el color, vigor y crecimiento de las plantas; además, se logra disminuir el tiempo de estadía de las plántulas en el vivero (Fonseca, 2004).

Las plantas son trasplantadas en promedio a los 15 días después de la germinación con un rango que varía de cuatro a 30 días; esta actividad es realizada en un $36 \%$ por los dueños de los viveros y el $64 \%$ 
Analisis de la produccion de viveros y de la comercializacion de plantulas en el area de influencia del canton Quevedo, provincia de los Ríos para el establecimiento de plantaciones de teca (Tectona grandis L.F.)r

Cuadro 1. Manejo de platabandas en viveros de teca. Quevedo, 2006.

\begin{tabular}{lcc}
\hline Manejo de platabandas & Número & Porcentaje \\
\hline Desinfección de platabandas & 5 & 35.7 \\
Surcos de tierra suelta & 2 & 14.3 \\
Las platabandas ya están construidas & 2 & 14.3 \\
Tierra de capa arable & 2 & 14.3 \\
Tierra arenosa & 2 & 14.3 \\
Cubetas de germinación & 1 & 7.1 \\
\hline Total & $\mathbf{1 4}$ & $\mathbf{1 0 0}$ \\
\hline
\end{tabular}

contrata personal. Para las actividades de trasplante se utilizan fundas negras de $12 \times 20 \mathrm{~cm}$ las mismas que son llenadas con tierra de huerta $(62 \%)$, arena $(15 \%)$ capa arable $(8 \%)$ y tierra con materia orgánica $(8 \%)$. El 7\% no realiza trasplante, produce exclusivamente pseudoestacas.
La producción de pseudoestacas (Foto 5) se realiza en un período de ocho meses. Este tipo de plántulas lo demanda clientes que tienen sus propiedades muy alejadas de los centros poblados y en terrenos un tanto inaccesibles a los vehículos por lo cual se hace necesario trasportar las pseudoestacas en acémilas, siendo esta la forma más utilizada

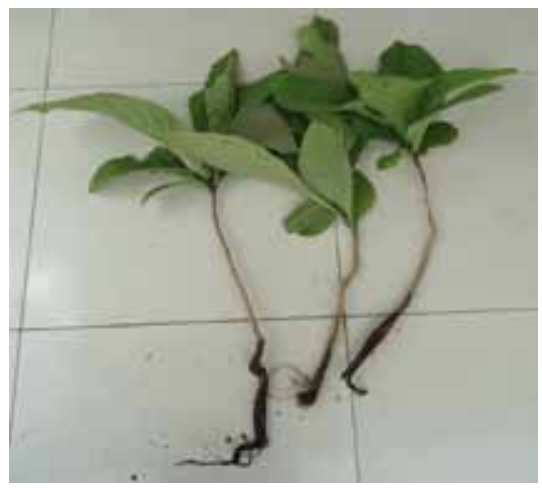

Foto 5. Producción de pseudoestacas de teca

El sistema de producción de pseudoestacas consiste en la siembra de semillas a chorro continuo en surcos de $70 \mathrm{~cm}$, realizando labores de raleo, poda, fertilización, riego y control de malezas. Cabe indicar, que el porcentaje de plantas aptas para la comercialización es del $50 \%$. Este sistema de propagación de la teca según Fonseca (2004) no es recomendable ya que se produce mucho daño al sistema radicular y un lento prendimiento de las plántulas en el campo; así como alta probabilidad de que las raíces sean invadidas por insectos y hongos, traduciéndose en mayores costos por resiembra y mantenimiento de la plantación y un largo período de estadía en el vivero.

El $57 \%$ de los productores de plántulas de teca han tenido bajos porcentajes de ataque de plagas y de hongos causando leves problemas a la raíz y al tallo, y el $43 \%$ no ha tenido problemas fitosanitarios en sus viveros. Para controlar las plagas utilizan productos químicos como el Malathion $\left(30 \mathrm{~cm}^{3}\right.$ por bomba de
$20 \mathrm{~L}$ ), Basudín ( $10 \mathrm{~cm}^{3}$ por bomba de $\left.20 \mathrm{~L}\right)$, Lorsban (70 $\mathrm{cm}^{3}$ por bomba de $\left.20 \mathrm{~L}\right)$ y Curacron $\left(25 \mathrm{~cm}^{3}\right.$ por bomba de $20 \mathrm{~L}$ ). Para el control de enfermedades causadas por hongos aplican Cobox (25 g por bomba de $20 \mathrm{~L}$ ).

\section{Costos}

El valor del jornal en la zona es en promedio de 5.29 dólares con un rango de cinco a siete dólares, siendo la moda cinco dólares. Cabe indicar que las horas que representa un jornal en la zona son en promedio de 5,54 horas, con un rango de cuatro a ocho horas de trabajo, siendo la moda cinco horas de labor diaria.

Los mayores costos directos están relacionados con una mayor tecnificación de la producción de las plántulas de teca. El costo de producción a nivel de pequeños viveristas y de productor de pseudoestacas fue de 0.07 USD y a nivel de productor tecnificado y de plántulas in vitro (Foto 6) de 0.19 USD (Figura 2). 


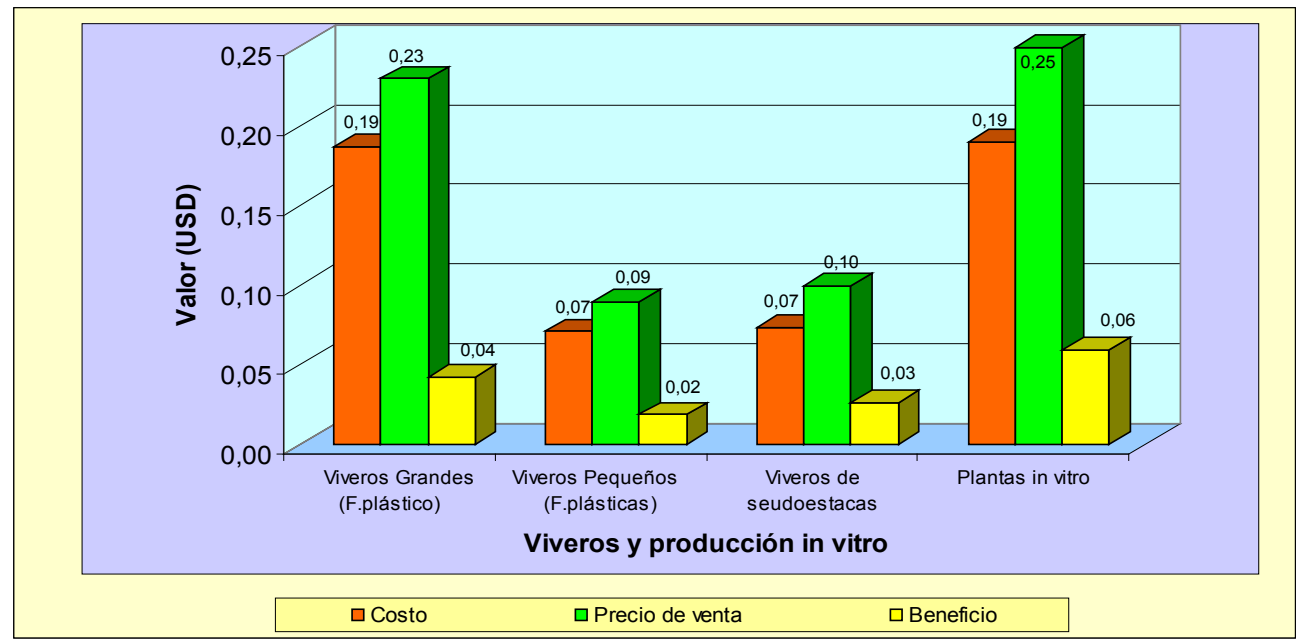

Figura 2. Costo, precio de venta y beneficio por plántula producida en vivero e in vitro en el cantón Quevedo y su área de influencia. Quevedo, 2006.

La mejor rentabilidad en la producción de las seguido de la producción de plántulas in vitro (31\%) plántulas se obtuvo a nivel de pseudoestacas (36\%), (Figura 3)

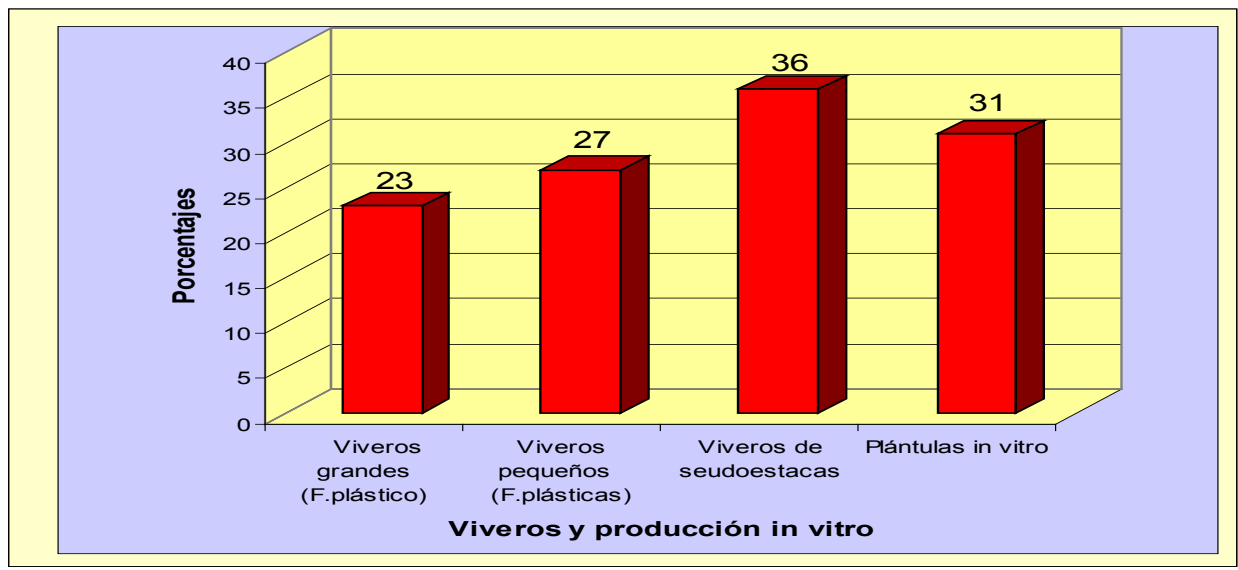

Figura 3. Rentabilidad de la producción en vivero e in vitro de plántulas de teca en el cantón Quevedo y su área de influencia. Quevedo, 2006.

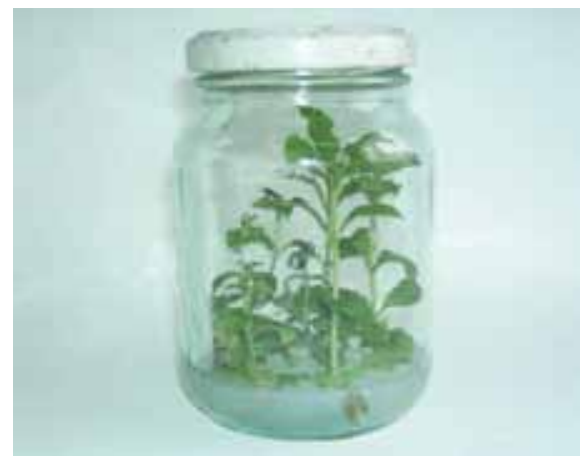

Foto 6. Producción de vitroplantas de teca en el Laboratorio de Biotecnología, UTEQ 
Aunque el precio de venta de las plántulas producidas tecnificadamente $(0.23$ USD) y el de las plántulas in vitro (0.25 USD), es mucho mayor que las producidas a nivel de pequeños viveristas $(0.09$ USD) y pseudoestacas (0.10 USD) es recomendable la inversión en los dos primeros tipos de plántulas por la mejor calidad de plantaciones que seguramente se establecerían.

\section{Comercialización}

Las plántulas son comercializadas en un 57\% entre los tres a cuatro meses de edad. El 29\% a los dos meses de edad y un 14\% a los ocho meses de edad; estos últimos, corresponden a las pseudoestacas que requieren más tiempo para su comercialización. La venta se realiza directamente del viverista al productor, y se realiza a pedido verbal de los clientes (93\%), mientras que, el porcentaje restante corresponde a pedidos bajo la modalidad de contrato.

Un 79\% de los viveristas venden sus plántulas a productores de teca de Esmeraldas, un $71 \%$ a productores de la provincia del Guayas, un $57 \%$ a productores de Manabí, un 43\% para Los Ríos y El Oro, y finalmente, un $14 \%$ para el Oriente ecuatoriano, lo cual indica que la demanda de las plántulas de teca es de carácter nacional (Región Litoral y Oriental).

\section{Oferta}

La oferta anual de plántulas de teca en Quevedo y su área de influencia es de 2’383,380 plántulas, siendo los viveristas de Quevedo los que proveen el $57 \%$ de la producción total (Figura 4).

\section{Demanda}

Tomando como base el crecimiento de las plantaciones de teca en el país aproximadamente 1,538 ha año ${ }^{-1}$, la demanda anual será de aproximadamente tres millones de plántulas (considerando densidades iniciales de 2 ×2 y 3×3 (3'845,000 y 1'708,718 plántulas, respectivamente), mientras que la oferta no supera los dos millones trescientos mil plántulas al año).

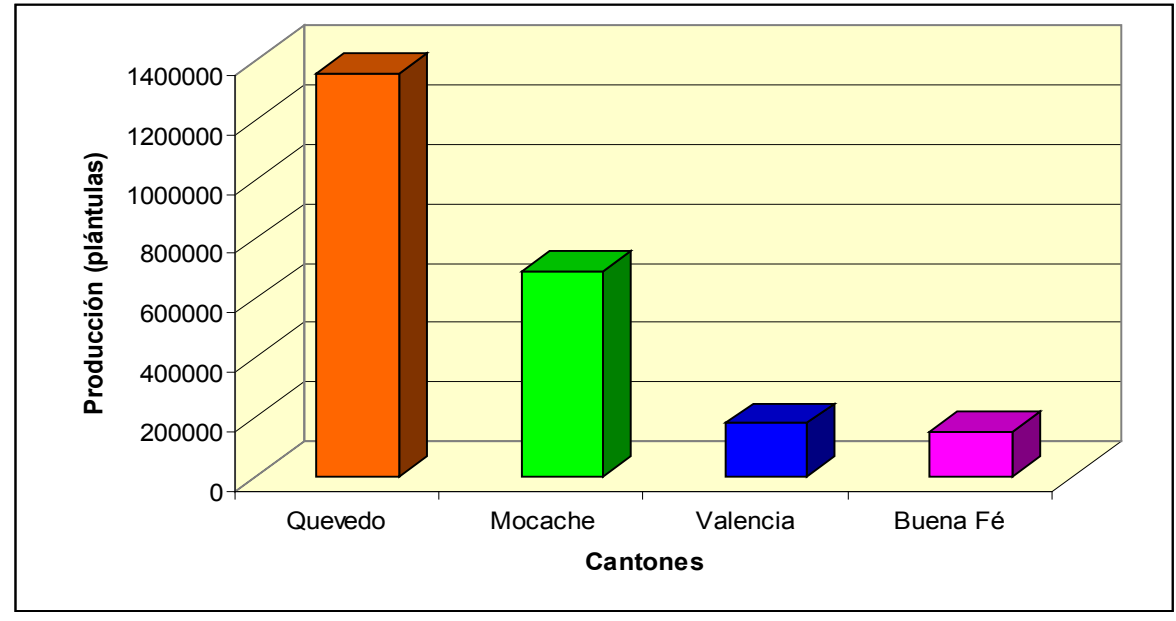

Figura 4. Producción anual de plántulas de teca. Quevedo, 2006

\section{Conclusiones}

$\mathrm{E}^{\mathrm{n}}$ n el cantón Quevedo están ubicados la mayor parte de los viveros de teca del país.

El costo de producción a nivel de pequeño viverista y de productor de pseudoestacas es de 0.07 USD y a nivel de productor tecnificado y de plántulas in vitro es de 0.19 USD.

La mejor rentabilidad en la producción de plántulas se obtiene a nivel de pseudoestacas $(36 \%)$, seguido de la producción de plántulas in vitro.

Aunque el precio de venta al público de las plántulas es mayor para los que producen tecnificadamente (0.23 USD) y el de las plántulas in vitro (0.25 USD), es recomendable esta inversión por la mejor calidad de las plantaciones que seguramente se establecerían.

Los pequeños viveristas tienen un alto potencial de emprendimiento, cuyas fortalezas se reflejan en la experiencia, tierras aptas, capacitación de las nuevas generaciones de viveristas, buenas relaciones con los productores de madera y otros viveristas de la zona, interés por mejorar su tecnología, etc.; mientras que, las debilidades se centran en el uso de semilla no certificada, poca capacidad organizativa y de comercialización;

La oferta actual de plántulas de teca no abastecerá la demanda para los próximos años, por lo que los pequeños viveristas deberán organizarse 
a nivel de asociaciones formalmente constituidas, toda vez que el Estado ecuatoriano está ejecutando proyectos de reforestación a nivel nacional, para lo cual deberán realizar ofertas competitivas y cumplir con los requisitos legales indispensables para captar este mercado y de esta manera acceder a la compra de semillas de calidad, organizar la producción de los viveros a través la candelarización de la producción, acceder a la capacitación continua, comercializar mayores volúmenes de plántulas, proveer el transporte , etc.

\section{LITERATURA CITADA}

CORMADERA (Corporación de Desarrollo Forestal y Maderero del Ecuador, EC). 2001. Guías técnicas para el establecimiento y manejo de plantaciones forestales productivas en el Litoral ecuatoriano. Proyecto piloto para la reforestación y rehabilitación de tierras forestales degradas en el Ecuador. PD 17/97. Rev. 3 (F). Quito. p. 1-35. (Libro 1).

Cháves, E; Fonseca, W. 1991. Teca, Tectona grandis L.f. especie de árbol de uso múltiple en América Central. Turrialba, C.R. CATIE. 60 p. (Serie Técnica. Informe técnico no. 179).
Fonseca W, 2004. Manual para productores de teca (Tectona grandis L. f) en Costa Rica. (en línea). Consultado 5 Oct. 2007. Disponible en www. fonafifo.com/text_files/proyectos/manual Productores Teca.pdf.115p.

Ministerio del Ambiente. Dirección Nacional Forestal 2006. Plan Nacional de Forestación y Reforestación (Versión ajustada). (en línea). Consultado 26 Sept. 2009. Disponible en www. ambiente.gov.ec/páginas_español/4ecuador/docs/ Planforestación.pdf.

Servicio de Información Agropecuaria del Ministerio de Agricultura y Ganadería del Ecuador 2005. (en línea). Consultado 19 Feb. 2006 SICA, 2005. Disponible en www.sica.gov.ec/www.sica.gov.ec/ agronegocios/biblioteca/teca.htm

Weaver, L. 1993. Tectona grandis L. f. Teak. SOITF-SM-64. New Orleáns, LA: U:S: Department of Agricultura, Forest Service, Southern Forest Experiment Station. $18 \mathrm{p}$. 